\title{
Winding Arrangement of a New Type Hollow Rotor BLDC Motor
}

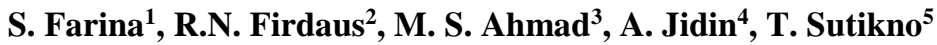 \\ 1,2,3,4Faculty of Electrical Engineering, Universiti Teknikal Malaysia Melaka, Malaysia \\ ${ }^{1,2,3,4}$ Electrical Machine Design, Power Electronics and Drives Research Group, CeRIA, UTeM, Malaysia \\ ${ }^{5}$ Universitas Ahmad Dahlan, Indonesia
}

\begin{tabular}{l} 
Article Info \\
\hline Article history: \\
Received Mar 15, 2018 \\
Revised Mar 22, 2018 \\
Accepted Jul 1, 2018 \\
\hline
\end{tabular}

\section{Keyword:}

Winding arrangement

Hollow rotor

BLDC

\begin{abstract}
This paper discusses about winding arrangement of fractional slot of a new type hollow rotor Brushless Direct Current (BLDC) motor. Hollow rotor has higher performance compared to other BLDC motor because it minimizes the unused flux below permanent magnet and maximize torque produce by the motor. It's also known that 8 pole motor is favorite used in industrial because it has an optimum space of permanent magnet for a smaller motor size. The number of pole will affect the maximum speed of the rotor. Thus, the objective of this research is to investigate the best winding arrangement for 8 pole of hollow rotor that could produce the highest electromagnetic performance. At starts, four combinations of slot number and coil sizes had been selected. Structural comparison in term of coil vector and winding arrangement is studied. Finite Element Method (FEM) had been used to simulate the parameters such as backemf and torque waveforms. It was convinced that 9 slot 8 pole with 0.6 size of coil produces the best performance. The confirmed model had been fabricated and measured. Both results from FEM and measurement are compared in term of backemf and torque where percentage differences are $7.4 \%$ and $8 \%$, respectively. As conclusion, this research shows the fundamental of winding arrangement of fractional slot of motor especially 8 pole motor.
\end{abstract}

Copyright $(0) 2018$ Institute of Advanced Engineering and Science. All rights reserved.

\section{Corresponding Author:}

R.N. Firdaus,

Faculty of Electrical Engineering, Universiti Teknikal Malaysia,

Hang Tuah Jaya, 76100 Durian Tunggal, Melaka, Malaysia

Email: norfirdaus@utem.edu.my

\section{INTRODUCTION}

The Brushlesss Direct Current (BLDC) motor is widely used in applications including appliances, automotive, aerospace, consumer, medical, automated industrial equipment and instrumentation. The BLDC motor is electrically commutated by power switches instead of brushes. Compared with a brushed DC motor or an induction motor, the BLDC motor has many advantages such as higher efficiency and reliability, lower acoustic noise, smaller and lighter, greater dynamic response, better speed versus torque characteristics, higher speed range and longer life. For instance, they own the highest torque density and efficiency among all types of motors. Moreover, thanks to their flux weakening capability, interior BLDC allow wide speed operation with constant power making them suitable for traction and transportation systems [1]. It is very important to pay high attention on combination of pole and slot numbers. Taeyong Yoon studied about magnetically induced vibration in a permanent-magnet BLDC with symmetric pole-slot configuration [2]. The author reports a numerical and experimental study of magnetically induced vibration associated with rotor and stator eccentricity and imperfect magnetization for 8-pole 6-slot symmetric BLDC motors. The results show that there is an optimal slot angle for minimum cogging torque, but this slot angle is not optimal for reducing magnetic forces. Many literatures has presented improvement methods for the reduction of 
cogging torque and torque ripple, such as the optimization of the tooth shape, magnet pole angle, combination of pole and slot numbers [3-4].

Additionally, an analysis process for predicting the vibration of motor and an experiment verification method also had been introduced. The validation of the analysis methods on the vibration in this paper is verified by the experiment as well as the effect of radial force (normal local force. Zhu et. al presents about influence of slot and pole number combinations on unbalanced magnetic force (UMF) in permanent magnet machine [5]. The author investigates the influence of slot and pole number combinations on the UMF. UMF may be divided into two components due to the radial and tangential traveling force waves. Jafari et.al has been concerned about three-dimensional finite-element-model investigation of axial-flux permanent magnet BLDC machines with similar pole and slot combination for electric vehicles [6]. The author investigates performance of axial-flux surface mounted permanent magnet BLDC machines with concentrated windings, considering a comparative study between two topologies with similar slot number and pole number: a 9 slot/10 pole machine (slot number and pole number differ by 1) and a 12 slot/10 pole machine (slot number and pole number differ by 2 ).

Cogging torque, winding inductance, output torque, and unbalanced torque exerted on bearing are obtained for the two $3.4 \mathrm{~kW}$ motors [6]. Sung et. al studies about flux fluctuations in rotor core according to pole and slot combination [7]. In some pole-slot combinations, the rotor's core loss is too important to be neglected because of high flux fluctuation in rotor core. The major reasons for the flux fluctuations of rotor are the pole-slot number combination, and the shapes of teeth and poles in the air-gap [8-9]. Mostafa et. al studies about influence of pole and slot combinations on magnetic forces and vibration in low-speed BLDC wind generators [10]. BLDC machines with concentrated windings could be beneficial in direct-drive wind generators since it is possible to reduce the size and weight of the generator [10]. The BLDC machines with concentrated windings having a large number of poles are compared to investigate the effect of pole and slot combinations on force and vibration characteristics in low speed generators. The BLDC machines with concentrated windings are becoming attractive in several applications [11]-[16]. They have several advantages over traditional BLDC machines with distributed windings such as short end-windings, low cogging torque, and lower cost module level manufacturing [17], [18]. It has been recognized in [19]-[22] that vibration level of modular machines can be considerably higher than traditional machines. This is mainly due to the presence of the low harmonic orders in the radial magnetic force distribution. Specific dimensional characteristics of the BLDC machines with high number of poles should also be considered from a vibration perspective. In the case of hollow rotor BLDC motor, there is still limited publication that discussed the winding arrangement especially for 8 pole rotor. Furthermore, hollow rotor motor for this research studies is considered as small motor size (40 mm diameter). Thus, this paper studies about the winding arrangement of small size hollow rotor BLDC motor. Hollow rotor topology could maximize the contribution of flux from permanent magnet and eliminate unused flux which limit the performance of standard spoke type BLDC motor [23]-[24]. As conclusion, this research shows the fundamental of winding arrangement of fractional slot of motor especially 8 pole motor.

\section{BASIC STRUCTURE}

The basic structure of conventional BLDC motor is shown in Figure 1 (a). Rotor is covered by silicon steel material, it will influence flux of permanent magnet to pass through the area below the ferromagnetic material. As a result, there is more leakage flux circling at the end of the permanent magnet as shown in Figure 1 (c). To reduce leakage at the end of permanent magnet, area below rotor is changed to hollow rotor as shown in Figure 1 (b). The arrangement of magnet in a hollow rotor is different with other BLDC motor where magnet is arranged to maximally reduce leakage flux. Hollow which consists of an air, has higher reluctance, thus channeling all flux to the nearest ferromagnetic material. In a hollow rotor spoke type BLDC motor, all flux will go around stator where it will maximize the usage of flux in the motor. Figure 1 (d) shows generated flux for hollow-rotor BLDC motor. Hollow which consists of an air, has higher reluctance, thus channeling all flux to the nearest ferromagnetic material. In a hollow rotor spoke type BLDC motor, all flux will go around stator where it will maximize the usage of flux in the motor.

Table 1 shows basic structure configuration for all combination and magnetic flux. Slot and pole parameter for each design is tabulated in Table 2. Each structure has the same value of rotor inner diameter, r1, rotor outer diameter, r2, stator inner diameter, r3, stator outer diameter, r4, stator tooth height, s1, stator width height, s2, air gap, ag, and permanent magnet volume which are $20 \mathrm{~mm}, 24.8 \mathrm{~mm}, 47 \mathrm{~mm}, 50 \mathrm{~mm}, 3$ $\mathrm{mm}, 1.5 \mathrm{~mm}, 0.2$, and $320 \mathrm{~mm} 2$, respectively. Pole for each design is 8 . The different between each design is only slot number. Varied parameter for each design is the number of turn and current where the number of turn is varied from 18 to 50 while current is varied from $2 \mathrm{~A}$ to $10 \mathrm{~A}$. Flux lines for all design is tabulated from $0 \mathrm{~T}$ to $2 \mathrm{~T}$ which is maximum value. All the flux for all design is recorded during backemf 
investigation. For all combination, flux value at stator is below 2 T. Besides flux lines, flux density for all slot combination is also recorded in Table 1. It can be seen that flux move from north pole of magnet towards air gap, up to stator and back to south pole.

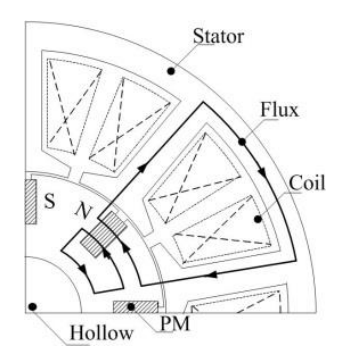

(a) Conventional BLDC structure

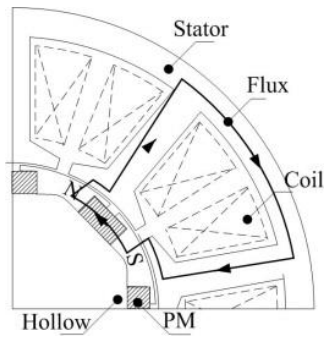

(b) Hollow-rotor structure

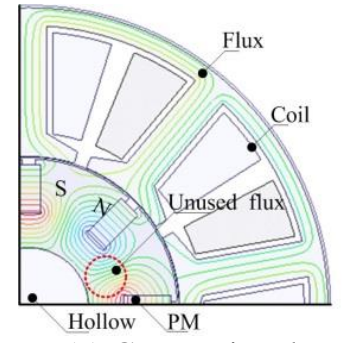

(c) Conventional generated flux

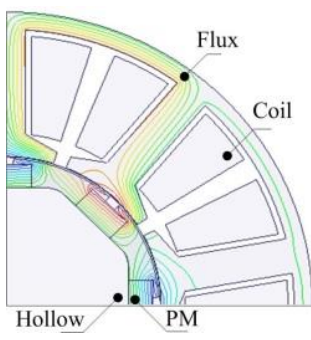

(d) Hollow-rotor generated flux

Figure 1. Hollow rotor topology

Table 1. Basic structure configuration and magnetic flux

Type Basic structure \&dimension Flux density

Table 2. Slot and pole configuration

\begin{tabular}{|c|c|c|c|c|c|}
\hline \multicolumn{6}{|c|}{ Fixed parameter } \\
\hline Parameters & & 6 slot 8 pole & 9 slot 8 pole & 12 slot 8 pole & 15 slot 8 pole \\
\hline Rotor inner diameter, $r_{1}$ & {$[\mathrm{~mm}]$} & 20 & 20 & 20 & 20 \\
\hline Rotor outer diameter, $r 2$ & {$[\mathrm{~mm}]$} & 24.8 & 24.8 & 24.8 & 24.8 \\
\hline Stator inner diameter, $r 3$ & {$[\mathrm{~mm}]$} & 47 & 47 & 47 & 47 \\
\hline Stator outer diameter, $r_{4}$ & {$[\mathrm{~mm}]$} & 50 & 50 & 50 & 50 \\
\hline Stator tooth height, $s_{1}$ & {$[\mathrm{~mm}]$} & 3 & 3 & 3 & 3 \\
\hline Stator width height, $s_{2}$ & {$[\mathrm{~mm}]$} & 1.5 & 1.5 & 1.5 & 1.5 \\
\hline Air gap, $a_{\mathrm{g}}$ & {$[\mathrm{mm}]$} & 0.2 & 0.2 & 0.2 & 0.2 \\
\hline Magnet volume & {$\left[\mathrm{mm}^{3}\right]$} & 320 & 320 & 320 & 320 \\
\hline \multicolumn{6}{|c|}{ Varied parameter } \\
\hline Number of turn, $N$ & & \multicolumn{4}{|c|}{$10,18,30,50$} \\
\hline Current, $I$ & {$[\mathrm{~A}]$} & \multicolumn{4}{|c|}{$2,4,6,8,10$} \\
\hline
\end{tabular}




\section{WINDING ARRANGEMENT}

\subsection{Pitch factor and distribution factor in motor windings}

For fractional slot and pole number motors, the slot pitch, $s_{\mathrm{p}}$ and pole pitch, $p_{\mathrm{p}}$ are generally given by equation (1) and equation (2) where $n$ is odd harmonics orders due to symmetrical permanent magnet distribution in the airgap region. Referring to Figure 2 (a), taking 6 slot 8 pole as an example, the coil is short chorded by a pitch angle $\alpha_{\mathrm{p}}$ as in equation (3) where $N_{\mathrm{s}}$ is number of slot and $P$ is pole of motor [25]. The pitch factor and distribution factor can be calculated using Z. Q. Zhu, M. S. Ahmad and I. Dahaman method [26]-[29] as shown below.

$$
\begin{gathered}
s_{p}=\frac{n 2 \pi}{N_{s}} \\
p_{p}=\frac{\pi}{p} \\
\alpha_{p}=\frac{n 2 \pi}{N_{s}}-\frac{\pi}{p}
\end{gathered}
$$

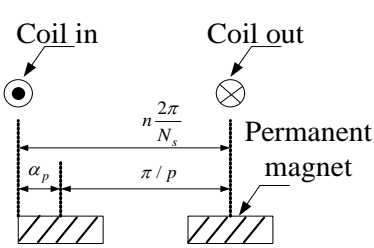

(a)

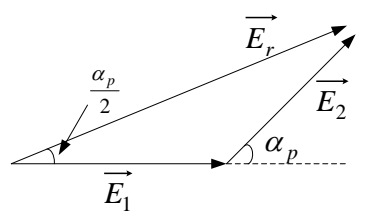

(b)

Figure 2. Pitch factors in 6 slot/8 pole motor. (a) single coil on stator tooth and pitch angle (b) induced emfs in both sides of a coil

Both sides of the coil will have an induced backemf, but because their angle is not zero, the backemf $E_{1}$ and $E_{2}$ are added vectorially to yield the coil backemf $E_{\mathrm{r}}$, whose magnitude is influenced by the pitch factor, defined as the ratio of the resultant vector, $E_{\mathrm{r}}$ to the algebraic sum of the individual vectors $E_{1}$ and $E_{2}$ as shown in Figure 2 (b). Therefore, the pitch factor, $K_{\mathrm{pn}}$ for 6 slot 8 pole is given by equation (4);

$K_{p n}=\cos \left(p \frac{\alpha_{p}}{2}\right)=\cos \left[\frac{p}{2}\left(\frac{n 2 \pi}{N_{s}}-\frac{\pi}{p}\right)\right]=-2 \sin ^{2} \frac{n P \pi}{2 N_{s}}-\sin ^{2} \frac{\pi}{4}$

For 6 slot 8 pole motor, each phase winding has 2 coil connected in series. Individually, each coil produces backemf vector as shown in Figure 3 (a). The combination of both coils to form phase winding which leads to highest distribution factor, $k_{\mathrm{dn}}$ will be chosen. Figure 3 (b) and Figure 3 (c) shows selection of coil per phase and derivation of distribution factor, respectively. The equation can be described as shown in equation (5) to (13).

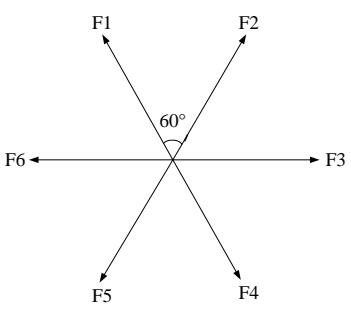

(a)

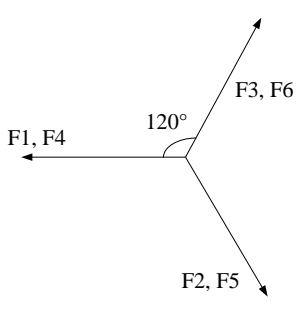

(b)

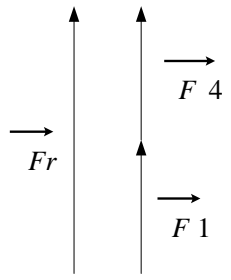

(c)

Figure 3. Coil emf vector and selection of coils per phase in 6 slot 8 pole motor. (a) mmf vectors for each coil wound around stator teeth in mechanical degree (b) Selection of coils for each phase in electrical degree (c) Derivation of distribution factors 
Distribution angle:

$\alpha_{d}=\pi-\frac{n p 2 \pi}{N_{s}}$

Resultant emf vector per phase:

$\overrightarrow{F_{r}}=\overrightarrow{F_{1}}+\overrightarrow{F_{4}}$

The distribution factor for 6 slot 8 pole, $k_{\mathrm{dn}}$ can be shown as:

$$
\begin{aligned}
& K_{d n}=\frac{\left|\overrightarrow{F_{r}}\right|}{\left|\overrightarrow{F_{1}}\right|+\left|\overrightarrow{F_{4}}\right|} \\
& K_{d n}=\frac{\left|\overrightarrow{F_{1}}\right|+|\overrightarrow{F 4}|}{\left|\overrightarrow{F_{1}}\right|+\left|\overrightarrow{F_{4}}\right|}=1 \\
& K_{d n}=\sin \frac{\pi}{2}
\end{aligned}
$$

Hence, the winding factor $K_{\mathrm{dpn}}$ for 6 slot 8 pole is the product of the pitch factor and distribution factor such that:

$$
\begin{aligned}
& K_{d p n}=\left(K_{p n}\right)\left(K_{d n}\right) \\
& K_{d p n}=\left[p \frac{\alpha_{p}}{2}\right]\left[\sin \frac{\pi}{2}\right] \\
& K_{d p n}=\left[\frac{p}{2}\left(\frac{n 2 \pi}{N_{s}}-\frac{\pi}{p}\right)\right]\left[\sin \frac{\pi}{2}\right] \\
& K_{d p n}=\left[-2 \sin \left(\frac{n P \pi}{N_{s}}+\frac{\pi}{4}\right) \sin \left(\frac{n P \pi}{2 N_{s}}-\frac{\pi}{4}\right)\right]\left[\sin \frac{\pi}{2}\right]
\end{aligned}
$$

Similar approach and method can be used for 9 slot 8 pole and 12 slot 8 pole motor. For 9 slot 8 pole, each winding consists of three coils connected in series. Figure 4 (a) shows how individual coils are selected to form the phase winding while Figure 4 (b) shows selection of coil for each phase. Coil 3, 8 and 4 are selected to form phase A windings. Polarities for the connection of coil 3 and 4, however have to be reversed in order to generate maximum backemf. Figure 4 (c) shows derivation of distribution factors. The resultant emf vector per phase is given by equation (14):

Derivation of distribution factors for 9 slot 8 pole:

$\overrightarrow{F_{r}}=\overrightarrow{F_{4}}+\overrightarrow{F_{x}}=\overrightarrow{F_{8}}+2 \overrightarrow{F_{4}} \cos \alpha_{d}$

The derivation factor can be derived as equation (15) and (17):

$$
K_{d n}=\frac{\left|\overrightarrow{F_{r}}\right|}{\left|\overrightarrow{F_{8}}\right|+\left|\overrightarrow{F_{3}}\right|+\left|\overrightarrow{F_{4}}\right|}
$$


$K_{d n}=\frac{\left|\overrightarrow{F_{8}}\right|+2\left|\overrightarrow{F_{4}}\right| \cos \alpha_{d}}{\left|\overrightarrow{F_{8}}\right|+\left|\overrightarrow{F_{3}}\right|+\left|\overrightarrow{F_{4}}\right|}$

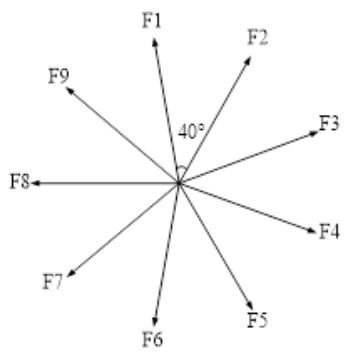

(a)

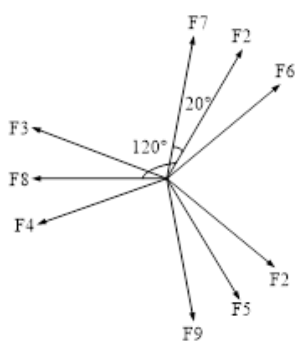

(b)

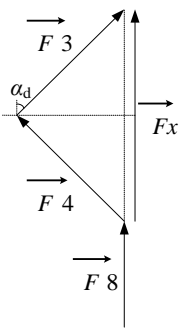

(c)

Figure 4. Coil emf vector and selection of coils per phase in 9 slot 8 pole motor. (a) mmf vectors for each coil wound around stator teeth in mechanical degree (b) Selection of coils for each phase in electrical degree (c) Derivation of distribution factors

$K_{d n}=\frac{1}{3}\left[1-2 \cos \left(\frac{n P 2 \pi}{N_{s}}\right)\right]$

Hence the winding factor for 9 slot 8 pole for the motor is given by equation (18) to (20):

$K_{d p n}=\left(K_{p n}\right)\left(K_{d n}\right)$

$K_{d p n}=\left[\frac{1}{3}\left[1-2 \cos \left(\frac{n P 2 \pi}{N_{s}}\right)\right]\right]\left[\cos \frac{P}{2}\left(\frac{\pi}{p}-\frac{n 2 \pi}{N_{s}}\right)\right]$

$K_{d p n}=\frac{1}{3} \sin \left[\frac{n P \pi}{N_{s}}\right]\left[1-2 \cos \left(\frac{n P 2 \pi}{N_{s}}\right)\right]$

For 12 slot 8 pole, each phase winding has 4 coils connected in series. Individually, each coil produces backemf vector as shown in Figure 5 (a). The combination of both coils to form phase winding which leads to highest distribution factor, $k_{\mathrm{dn}}$ will be chosen. Figure 5 (b) and Figure 5 (c) shows selection of coil per phase and derivation of distribution factor, respectively. The derivation factor for 12 slot 8 pole can be derived as shown in equation (21) and (23).

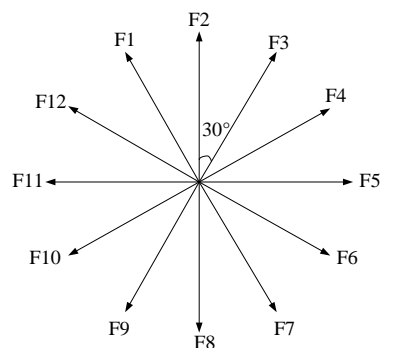

(a)

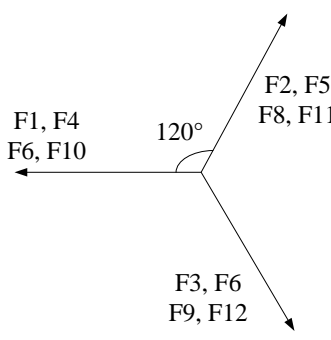

(b)

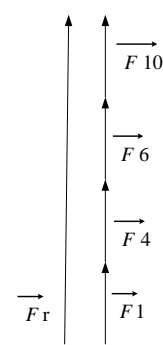

(c)

Figure 5. Coil emf vector and selection of coils per phase in 12 slot 8 pole motor. (a) mmf vectors for each coil wound around stator teeth in mechanical degree (b) Selection of coils for each phase in electrical degree (c) Derivation of distribution factors 


$$
\begin{aligned}
& K_{d n}=\frac{\left|\overrightarrow{F_{r}}\right|}{\overrightarrow{\left|F_{1}\right|}+\left|\overrightarrow{F_{4}}\right|+\left|\overrightarrow{F_{6}}\right|+\left|\overrightarrow{F_{10}}\right|} \\
& K_{d p n}=\left[\sin \frac{\pi}{2}\right]\left[\operatorname{coc}\left(\frac{\pi}{2}-\frac{n P \pi}{N s}\right)\right] \\
& K_{d p n}=\left[\sin \frac{\pi}{2}\right]\left[\sin \left(\frac{n P \pi}{N s}\right)\right]
\end{aligned}
$$

\subsection{Coil Arrangement}

Table 3 shows coil vector and winding arrangement for each phase which is separated between dotted line for all hollow rotor slot and combination. Each arrangement is design for three phase configuration. For 6 slot 8 pole each phase has two winding.

Table 3. Coil vector and coil arrangement

Type

Each phase has four winding respectively which are $\mathrm{C} 4, \mathrm{C} 6, \mathrm{C} 10, \mathrm{C} 13$ for phase $\mathrm{A}, \mathrm{C} 2, \mathrm{C} 5, \mathrm{C} 8, \mathrm{C} 11$ for phase B and C3, C6, C9, C12 for phase C. Last configuration is for 15 slot 8 pole. For phase A, coil configuration is $\mathrm{C} 1, \mathrm{C} 3, \mathrm{C} 5, \mathrm{C} 12, \mathrm{C} 14$, while phase $\mathrm{B}$ is $\mathrm{C} 2, \mathrm{C} 4, \mathrm{C} 6, \mathrm{C} 8, \mathrm{C} 10$ and phase $\mathrm{C}$ is $\mathrm{C} 7, \mathrm{C} 9, \mathrm{C} 11$, $\mathrm{C} 13, \mathrm{C} 15$. Phase $\mathrm{A}, \mathrm{B}$ and $\mathrm{C}$ winding is $\mathrm{C} 1$ and $\mathrm{C} 4, \mathrm{C} 3$ and $\mathrm{C} 6, \mathrm{C} 2$ and $\mathrm{C} 5$, respectively. Each phase coil configuration is shown in Table 4. For 9 slot 8 pole, each phase has three winding which is $\mathrm{C} 1, \mathrm{C} 2, \mathrm{C} 3$ for 
phase A, whereas C7, C8, C9 and C4, C5, C6 for phase B and phase C. Next coil arrangement is for 12 slot 8 pole.

Table 4. Coil configuration for each phase

\begin{tabular}{ccccc}
\hline Phase & 6 slot 8 pole & 9 slot 8 pole & 12 slot 8 pole & 15 slot 8 pole \\
\hline A & C1, C4 & $\mathrm{C}^{\prime}, \mathrm{C} 2, \mathrm{C} 3^{\prime}$ & $\mathrm{C} 4, \mathrm{C} 6, \mathrm{C} 10, \mathrm{C} 13$ & $\mathrm{C} 1, \mathrm{C} 3^{\prime}, \mathrm{C} 5, \mathrm{C} 12, \mathrm{C} 14^{\prime}$ \\
$\mathrm{B}$ & $\mathrm{C} 3, \mathrm{C} 6$ & $\mathrm{C}^{\prime}, \mathrm{C} 8, \mathrm{C} 9^{\prime}$ & $\mathrm{C} 2, \mathrm{C} 5, \mathrm{C} 8, \mathrm{C} 11$ & $\mathrm{C} 2, \mathrm{C} 4^{\prime}, \mathrm{C} 6, \mathrm{C} 8^{\prime}, \mathrm{C} 10$ \\
$\mathrm{C}$ & $\mathrm{C} 2, \mathrm{C} 5$ & $\mathrm{C}^{\prime}, \mathrm{C} 5, \mathrm{C} 6^{\prime}$ & $\mathrm{C} 3, \mathrm{C} 6, \mathrm{C} 9, \mathrm{C} 12$ & $\mathrm{C} 7, \mathrm{C} 9^{\prime}, \mathrm{C} 11, \mathrm{C} 13^{\prime}, \mathrm{C} 15$ \\
\hline
\end{tabular}

\section{PARAMETER FOR ANALYSIS}

This research is aimed to study the best possible combination of slot number for 8 pole hollow rotor. The general methodology is shown in Figure 6 (a). Firstly, four combination of slot and pole is selected which are 6 slot 8 pole, 9 slot 8 pole, 12 slot 8 pole and 15 slot 8 pole. All the parameter for design in term of rotor inner diameter, $r_{1}$, rotor outer diameter, $r_{2}$, stator inner diameter, $r_{3}$, stator outer diameter, $r_{4}$, stator tooth height, $s_{1}$ stator width height, $s_{2}$, air gap, $a_{\mathrm{g}}$, and permanent magnet volume is fixed. Only winding arrangement of the motor is different. The design carried out by using computer aided software (CAD) software. Coil vector and winding arrangement of each combination is properly designed. Analysis parameter for all design in term of backemf, stator flux density, rotor flux density, static torque and transient torque is simulated by using FEM analysis. During backemf analysis, diameter of coil is varied from $0.4 \mathrm{~mm}$ to 1.0 $\mathrm{mm}$. One design from all four combination will be choosen and fabricated based on the best motor performance.

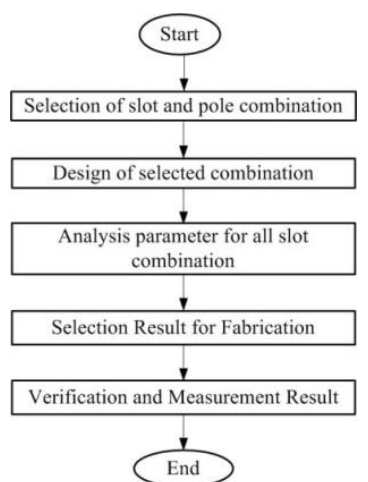

(a) General methodology

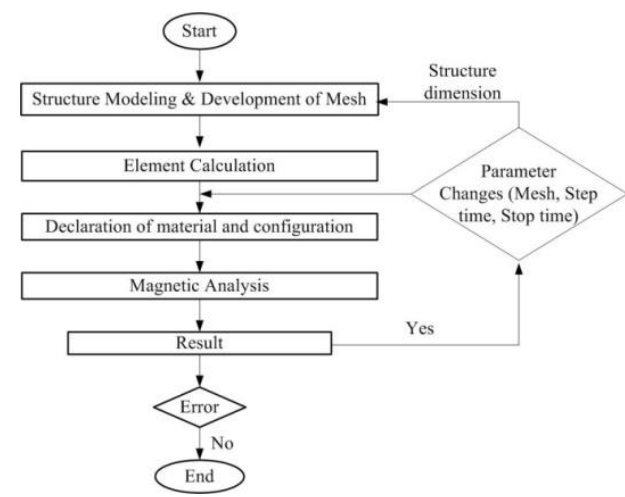

(b) Flowchart FEM modelling

Figure 6. Research methodology

The Finite Element Method (FEM) starts with the developing of the structure modelling of the electric machine as shown in Figure 6 (b). For structure modelling, user is required to sketch the geometry in (CAD) and imports the geometry files in the FEM software. Meshing calculation for the model will be carried out before element calculation took place. It requires time to develop the model depends on the model structure. When mesh development is completed, system will start element calculation. At this point, all the calculation for FEM will be conducted. After that, declaration of material and configuration will be carried out. During this stage, setup for material and other configuration such as simulation time, air gap setting, motion setup and boundaries will be selected. Magnetic analysis will be simulated and result for each analysis will be recorded. There are some parameter which will change during FEM calculation.

\section{INVESTIGATION OF SLOT NUMBER OF 8 POLE HOLLOW ROTOR}

Figure 7 shows the simulation result using FEM analysis for backemf. Maximum speed for the motor is fixed for $1000 \mathrm{rpm}$. Figure 7 (a) is result of backemf for 6 slot 8 pole. Maximum backemf is $6.08 \mathrm{~V}$ at for coil size of $0.4 \mathrm{~mm}$ and minimum backemf is $0.24 \mathrm{~V}$ for coil size of $1.0 \mathrm{~mm}$. Percentage different between each coil size is $42 \%$. Figure 7 (b) is the result of backemf for 9 slot 8 pole. Maximum backemf is 
$9.2 \mathrm{~V}$ for coil size of $0.4 \mathrm{~mm}$ while minimum backemf is $0.38 \mathrm{~V}$ for coil size of $1.0 \mathrm{~mm}$. Percentage different between each point is $40 \%$. Figure 7 (c) is the result of backemf for 12 slot 8 pole. Maximum backemf is $12.12 \mathrm{~V}$ for coil size of $0.4 \mathrm{~mm}$ while minimum backemf is $0.48 \mathrm{~V}$ for coil size of $1.0 \mathrm{~mm}$. Percentage different between each point is $39 \%$. Figure 7 (d) is the result of backemf for 15 slot 8 pole. Maximum backemf is $12.5 \mathrm{~V}$ for coil size 0.4 of $\mathrm{mm}$ while minimum backemf is $0.5 \mathrm{~V}$ for coil size of $1.0 \mathrm{~mm}$. Percentage different between each point is $40 \%$. There are some changes of backemf when coil size is change from $0.4 \mathrm{~mm}$ to $1.0 \mathrm{~mm}$. Backemf increase linearly with the increase of speed. The value for backemf for all design at speed $200 \mathrm{rpm}$ is below $3 \mathrm{~V}$. Value of backemf during maximum speed $1000 \mathrm{rpm}$ for 6 slot 8 pole is more than $6 \mathrm{~V}$ while maximum value for design 9 slot is more than $9 \mathrm{~V}$. The design of 12 slot 8 pole and 15 slot 8 pole has maximum backemf value which is more than $12 \mathrm{~V}$.

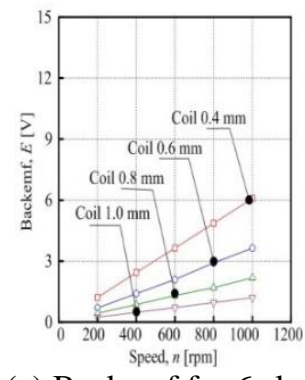

(a) Backemf for 6 slot 8 pole

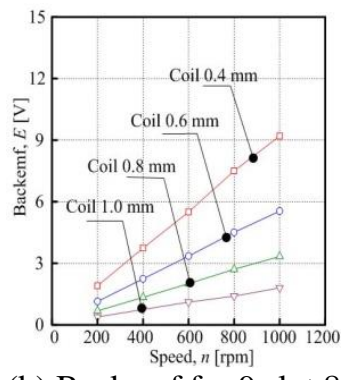

(b) Backemf for 9 slot 8 pole

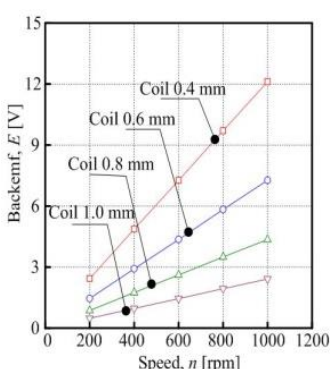

(c) Backemf for 12 slot 8 pole

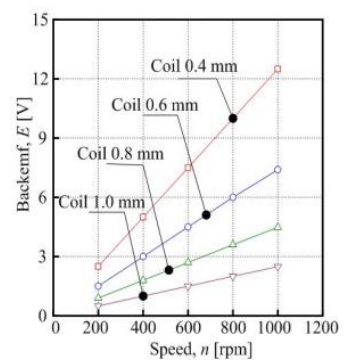

(d) Backemf for 15 slot 8 pole

Figure 7. Backemf FEM analysis

For all design, maximum backemf occur when coil size of $0.4 \mathrm{~mm}$ is used while minimum backemf occur when coil size of $1.0 \mathrm{~mm}$ is used. This is because, smaller diameter coil size will have higher number of turn. Figure 8 shows maximum torque analysis by using FEM. All torque result is captured at speed 1000 $\mathrm{rpm}$ and current range from $2 \mathrm{~A}$ to $10 \mathrm{~A}$. Figure 8 (a) is maximum torque result for 6 slot 8 pole. Maximum torque $0.69 \mathrm{Nm}$ occur for current $10 \mathrm{~A}$ when coil $0.4 \mathrm{~mm}$ is used while minimum torque is $0.04 \mathrm{Nm}$ for current 2 A of coil size $0.2 \mathrm{~mm}$. Minimum torque captured during $0.4 \mathrm{~mm}$ coil used is $0.21 \mathrm{Nm}$. Percentage different between maximum and minimum torque at this point is $69.5 \%$. Figure 8 (b) is maximum torque result for 9 slot 8 pole. Maximum torque appears at coil size $1.16 \mathrm{Nm}$ while minimum torque is $0.06 \mathrm{Nm}$ at coil size of $1.0 \mathrm{~mm}$. When coil $0.4 \mathrm{~mm}$ is used, minimum torque is $0.32 \mathrm{Nm}$.

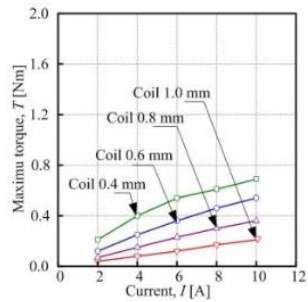

(a) Maximum torque for 6 slot 8 pole

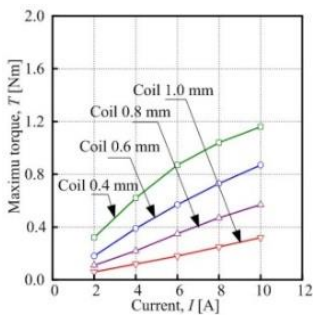

(b) Maximum torque for 9 slot 8 pole

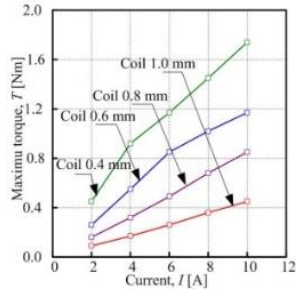

(c) Maximum torque for 12 slot 8 pole

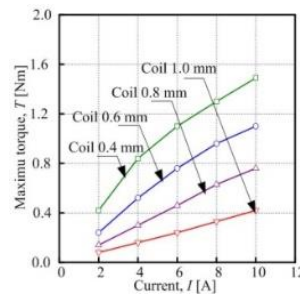

(d) Maximum torque for 15 slot 8 pole

Figure 8. Maximum torque FEM analysis

Percentage different for torque at this coil size is $72.4 \%$. Figure 8 (c) is the maximum torque result for 12 slot 8 pole. Maximum torque for this design is $1.74 \mathrm{Nm}$ for coil $0.4 \mathrm{~mm}$ while minimum torque is 0.09 $\mathrm{Nm}$ for $1.0 \mathrm{~mm}$ of coil size. When coil $0.4 \mathrm{~mm}$ is used, minimum torque is $0.45 \mathrm{Nm}$. Percentage different for torque for this coil size is $74.1 \%$. Figure 8 (d) is maximum torque result for 15 slot 8 pole. Maximum torque is $1.49 \mathrm{Nm}$ at coil size $0.4 \mathrm{~mm}$ while minimum torque is $0.08 \mathrm{Nm}$ at coil size $1.0 \mathrm{~mm}$. When coil $0.4 \mathrm{~mm}$ is used, minimum torque is $0.42 \mathrm{Nm}$. Percentage different for torque for this coil size is $71.8 \%$. All slot and pole design has the same similarity where torque increase when current is increased while torque is reduced when coil sized used is higher. At surrounding permanent magnet area there is a magnetic field and this gives 
a flow of magnetic energy. It is the flow of energy that is call magnetic flux. Magnetic flux flows from north pole of a permanent magnet to its south pole. Figure 9 shows flux density for stator and rotor. At this point, current is applied from range $2 \mathrm{~A}$ to $10 \mathrm{~A}$. The flux produce include magnetic flux from permanent magnet and current. The flux density is amount of flux through an area as shown in equation (17) where B is flux density, $\phi$ is flux and $\mathrm{A}$ is area of passing flux.

$B=\frac{\phi}{A}$

Figure 9 is result of stator flux density for all slot and pole combination for coil diameter range from $0.4 \mathrm{~mm}$ to $1.0 \mathrm{~mm}$. Stator flux density and rotor flux density is defined at maximum speed $1000 \mathrm{rpm}$. Figure 9 (a) is the result of stator flux density for coil diameter size of $0.4 \mathrm{~mm}$. The highest stator flux density is $1.98 \mathrm{~T}$ for 12 slot 8 pole design while minimum stator flux density is $1.01 \mathrm{~T}$ for 9 slot 8 pole winding arrangement. The stator flux density for 12 slot 8 pole and 15 slot 8 pole arrangement has only small different of flux density which is $2.3 \%$. Stator flux density for design of 6 slot 8 pole and 9 slot 8 pole has different of $2.1 \%$ for current of $4 \mathrm{~A}$ to $10 \mathrm{~A}$ while at $2 \mathrm{~A}$ the different is $32.5 \%$. Figure 9 (b) shows rotor flux density for coil diameter size of $0.4 \mathrm{~mm}$. Maximum flux density is $1.46 \mathrm{~T}$ for 12 slot 8 pole arrangement while minimum flux density for rotor is $0.75 \mathrm{~T}$ for 6 slot 8 pole arrangement. The 12 slot 8 pole and 9 slot 8 pole arrangement has the most nearest value of flux density which the percentage different is between $33.3 \%$ to $11.23 \%$. Figure 9 (c) shows stator flux density for coil diameter $0.6 \mathrm{~mm}$. The maximum stator flux density appears for 12 slot 8 pole design which is $1.28 \mathrm{~T}$ while minimum flux density is $1.19 \mathrm{~T}$ for 9 slot 8 pole arrangement. For this coil size, 9 slot 8 pole has the lowest stator flux density when the current is change from 2 A to 10 A where the maximum flux density at this point is $1.62 \mathrm{~T}$. Figure 9 (d) shows result of rotor flux density for all slot and pole combination. Result for rotor flux density is investigated for current 2 A to $10 \mathrm{~A}$ at coil size 0.6 $\mathrm{mm}$. Maximum rotor flux density occur at current $10 \mathrm{~A}$ for design 15 slot 8 pole which is $1.15 \mathrm{~T}$ while minimum rotor flux density is $0.58 \mathrm{~T}$ at current $6 \mathrm{~A}$ for 6 slot 8 pole design. Rotor flux density increase linearly with the increase of current for all design. The highest rotor flux density appear for 12 slot 8 pole while lowest rotor flux density occur for 6 slot 8 pole design.

Figure 9 (e) shows stator flux density for coil size of $0.8 \mathrm{~mm}$ where maximum flux density is $1.71 \mathrm{~T}$ for 15 slot 8 pole and 12 slot 8 pole arrangement. Figure 9 (f) shows rotor flux density result for coil diameter size of $0.8 \mathrm{~mm}$. The maximum flux density is $1.08 \mathrm{~T}$ for 15 slot 8 pole and 12 slot 8 pole arrangement. The minimum rotor flux density is $0.46 \mathrm{~T}$ for 9 slot 8 pole arrangement. Figure $9(\mathrm{~g})$ shows stator flux density result for coil size of $1.0 \mathrm{~mm}$. The maximum stator flux density is $2.07 \mathrm{~T}$ for 15 slot 8 pole combination while minimum stator flux density is $0.95 \mathrm{~T}$ for 9 slot 8 pole arrangement. It can be seen from the graph stator flux density for 6 slot 8 pole and 12 slot 8 pole arrangement has only small different which is less than $5 \%$. Figure 9 (h) shows the result for rotor flux density when $1.0 \mathrm{~mm}$ coil size is used. The maximum flux density is $1.35 \mathrm{~T}$ for 15 slot 8 pole design while minimum flux density is 0.35 for 9 slot 8 pole arrangement. The minimum stator flux density is $0.95 \mathrm{~T}$ for 9 slot 8 pole arrangement. From result 9 (a), 9 (c), 9 (e) and 9 $(\mathrm{g})$, it can be seen that 9 slot 8 pole arrangement has the lowest stator flux density which makes it on the top reasonable design among all other combination. When it is compared to rotor flux density, 9 slot 8 pole design has the range of flux density below 1.5 T. From all the result from Figure (8) and Figure (9), it is concluded that coil size of $0.6 \mathrm{~mm}$ is the best coil size used for motor prototype. This is because, when bigger coil size is used, lower torque is obtained while when smaller coil size is used, higher flux density will be produced. This will lowered the motor performance where higher flux density will bring motor performance to be saturated.

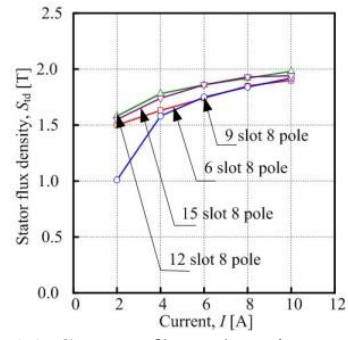

(a) Stator flux density at $0.4 \mathrm{~mm}$

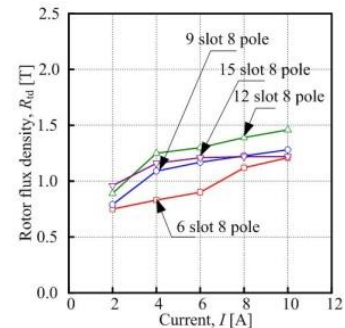

(b) Rotor flux density for 0

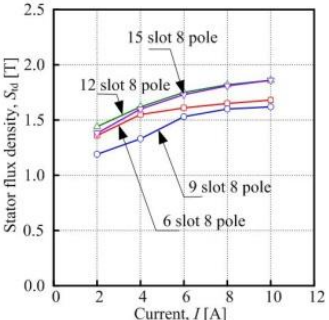

(c) Stator flux density at $0.6 \mathrm{~mm}$

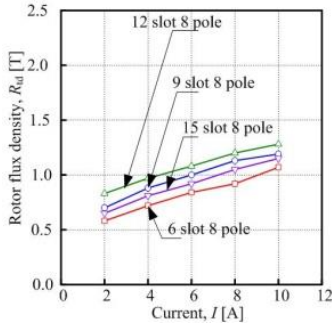

(d) Rotor flux density for $0.6 \mathrm{~mm}$ 


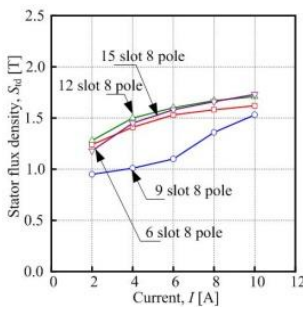

(e) Stator flux density at $0.8 \mathrm{~mm}$

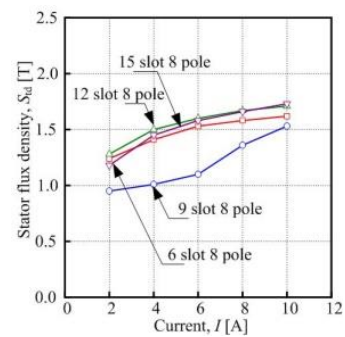

(f) Rotor flux density for $0.8 \mathrm{~mm}$

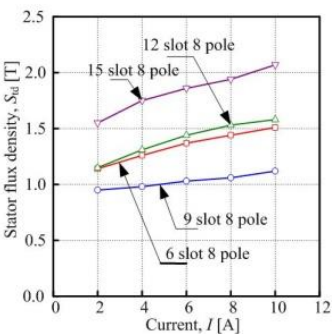

(g) Stator flux density at $1.0 \mathrm{~mm}$

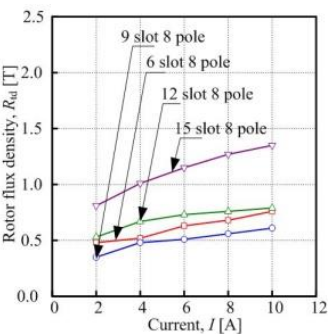

(h) Rotor flux density for $1.0 \mathrm{~mm}$

Figure 9. Flux density

\section{PROTOTYPE AND MEASUREMENT SETUP}

Figure 10 (a) and Figure 10 (b) is structural configuration and cross sectional view of hollow rotor BLDC motor. The prototypes includes stator, rotor, magnet and coil. Figure 10 (c) is exploded view of hollow rotor. The complete prototype is shown in Figure $10(\mathrm{~d})$. Casing length, $c_{\mathrm{l}}$, casing width, $c_{\mathrm{w}}$, and casing height, $c_{\mathrm{h}}$ is set to $50 \mathrm{~mm}, 50 \mathrm{~mm}$ and $10 \mathrm{~mm}$, respectively. Stator and rotor is made from laminated steel. The fabricated hollow rotor is 9 slot 8 poles with the winding of coil diameter size $0.6 \mathrm{~mm}$. The heat produce by coil during motor operation will be dissipated to surrounding air. There are two casing used which will cover front and back of the motor. To fit both casing with the stator, four set of screw will be used at each end of the casing. Material used for silicon steel is standard silicon J1: 50800, permanent magnet is Neodynium Nd 42 and copper for coil. Table 5 shows hollow rotor specification for the fabricated motor. Casing length, $c_{1}$, casing width, $c_{\mathrm{w}}$ and casing height, $c_{\mathrm{h}}$ is $50 \mathrm{~mm}, 50 \mathrm{~mm}$ and $10 \mathrm{~mm}$, respectively. Number of slot and pole for the for the fabricated motor is 9 slots 8 pole. The permanent magnet volume is $320 \mathrm{~mm}$. Maximum current for hollow rotor operation is $6 \mathrm{~A}$. Number of turn set for each winding is 30 . Air gap, $a_{\mathrm{g}}$ is $0.5 \mathrm{~mm}$.

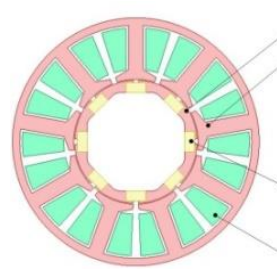

(a) Structural configuration of hollow rotor

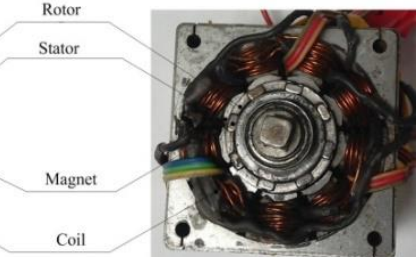

(b) Cross sectional view

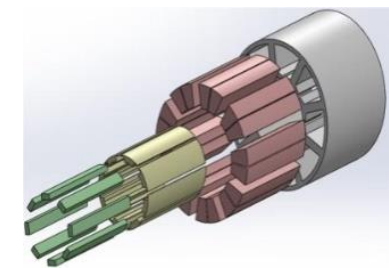

(c) Exploded view of hollow rotor

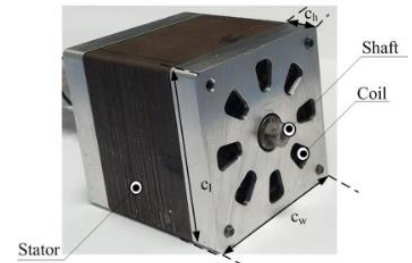

(d) Fabricated motor

Figure 10. Prototype of hollow rotor

Table 5. Hollow rotor specification

\begin{tabular}{lcc}
\hline \multicolumn{1}{c}{ Parameter } & Value \\
\hline Casing length, $c_{1}$ & {$[\mathrm{~mm}]$} & 50 \\
Casing width, $c_{\mathrm{w}}$ & {$[\mathrm{mm}]$} & 50 \\
Casing height, $c_{\mathrm{h}}$ & {$[\mathrm{mm}]$} & 10 \\
Number of slot & & 9 \\
Number of pole & & 8 \\
Permanent magnet & {$\left[\mathrm{mm}^{3}\right]$} & 320 \\
Maximum current & {$[\mathrm{A}]$} & 6 \\
Num of turn & {$[\mathrm{mm}]$} & 30 \\
Air gap, $a_{\mathrm{g}}$ & {$[\mathrm{mm}]$} & 0.5 \\
\hline
\end{tabular}

\subsection{Measurement setup}

Figure 11 (a) shows diagram for torque and speed measurement setup. Speed sensor will measure the speed in rpm which will be shown by digital speed indicator. Torque sensor is connected to dynamic strain amplifier which allows the data to be presented in oscilloscope. For this experiment, a BLDC driver is used to operate hollow rotor BLDC motor. $15 \mathrm{~V}$ is being supply to the BLDC driver to trigging the switching 
device (MOSFET). $5 \mathrm{~V}$ is set for supplying hall effect sensor, meanwhile the motor supply is set for $12 \mathrm{~V}$ initially. Then, for next experiment the motor supply is varied to $24 \mathrm{~V}$ and $48 \mathrm{~V}$. Three phase wye connection is set to BLDC driver. Powder brake is connected to torque sensor shaft. Other power supply is used for powder brake with $0.5 \mathrm{~V}, 1.0 \mathrm{~V}, 1.5 \mathrm{~V}$ and $2.0 \mathrm{~V}$ to provide different value of braking torque. Figure 11 (b) shows measurement setup of torque and speed characteristic in the laboratory.

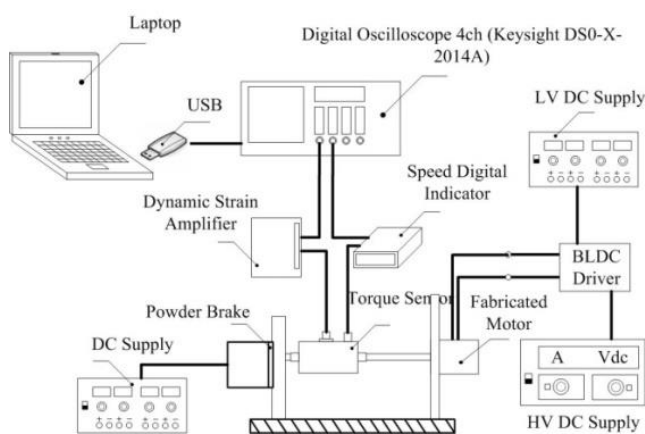

(a) Torque and speed measurement setup

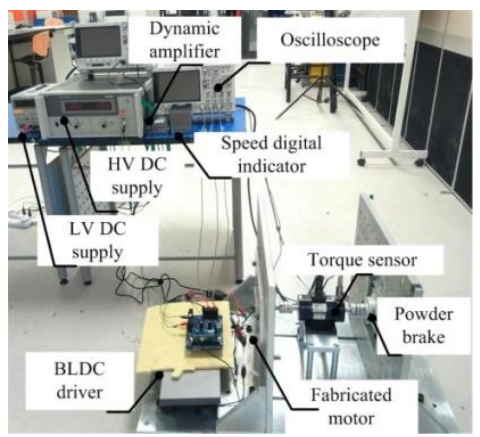

(b) Laboratory setup

Figure 11. Measurement setup

\section{VERIFICATION RESULT}

Figure 12 shows verification of hollow rotor by using FEM simulation and measurement. The current is fixed 6 A. Figure 12 (a) shows hollow rotor back emf characteristic. Maximum back emf using FEM is $5.4 \mathrm{~V}$ while measurement result is $5 \mathrm{~V}$. Percentage different is $7.4 \%$ between simulation and measurement. For the measurement of back emf, a constant speed of $1000 \mathrm{rpm}$ is given to the motor for the recording purpose. Only phase A is compared for FEM simulation and measurement because all the three phases have the same pattern but with different phases. Figure 12 (b) shows maximum backemf for measurement and FEM. Maximum speed for backemf is $1000 \mathrm{rpm}$. Minimum backemf at $200 \mathrm{rpm}$ during FEM and measurement is $1.14 \mathrm{~V}$ and $1.026 \mathrm{~V}$, respectively. Meanwhile maximum backemf is $5.54 \mathrm{~V}$ and $4.986 \mathrm{~V}$ for measuremet and FEM at $1000 \mathrm{rpm}$. Backemf increase linearly with speed. Percentage different between FEM and measuremet is $10 \%$. Figure 12 (c) shows the comparison result for static torque characteristic. The maximum value of torque during measurement is $0.31 \mathrm{Nm}$ while the maximum value of torque using FEM simulation is $0.39 \mathrm{Nm}$. The percentage error between measurement and simulation is about $8 \%$. During measurement of static torque, motor will be in static position where motor will be rotating without the use of any driver. Static torque is compared with simulation when pure DC current source is given in phase winding. Dynamic torque is shown in Figure 12 (d). Maximum dynamic torque from measurement is $0.31 \mathrm{Nm}$ at current $5.4 \mathrm{~A}$, while from FEM is $0.34 \mathrm{Nm}$. The average value of dynamic torque from FEM compared to measurement has percentage of difference is $4 \%$. As a conclusion, all result has good agreement between simulation and measurement.

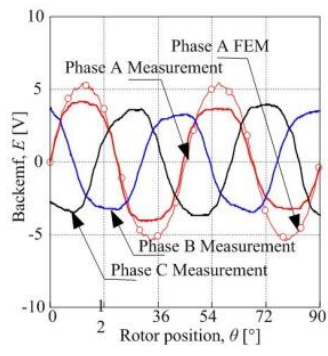

(a) Backemf at 1000 rpm

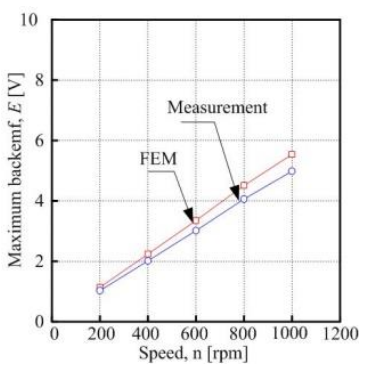

(b) Maximum backemf

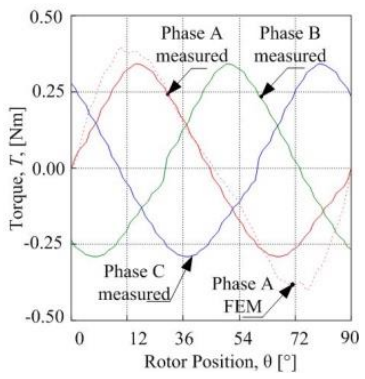

(c) Static torque

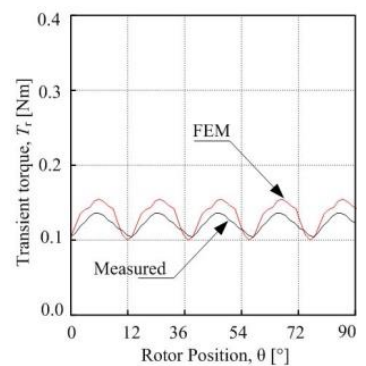

(d) Transient torque

Figure 12. Verification result of hollow rotor 
Torque ripple measures as the difference in maximum torque and minimum torque over average torque of one revolution as shown in equation (18).

$T_{\text {ripple }}=\frac{T_{\max }-T_{\min }}{T_{\text {ave }}} \times 100$

Whereas, $T_{\max }$ is the maximum torque, $T_{\min }$ is the minimum torque while $T_{\text {ave }}$ is the average torque. Basically, torque ripple is generated by the pulsation of the cogging torque, the variation of induction with the rotor position, and the interaction between the magnet-motive force of stator and the magnetic force of the permanent magnet. The result for torque ripple is tabulated as in Table 6. $T_{\max }$ during measurement is 0.31 $\mathrm{Nm}$ while $T_{\max }$ during FEM is $0.34 \mathrm{Nm}$. $T_{\min }$ during measurement is $0.23 \mathrm{Nm}$ while $T_{\min }$ during FEM analysis is $0.22 \mathrm{Nm}$. The different for $T_{\min }$ during measurement and FEM is $4.3 \%$. $T_{\text {ave }}$ during measurement is 0.27 $\mathrm{Nm}$ while $T_{\text {ave }}$ during FEM is $0.28 \mathrm{Nm}$. For $T_{\text {ave, }}$, both result has $3.5 \%$ differences. Based on the data, $T_{\text {ripple }}$ is calculated. $T_{\text {ripple }}$ during measurement is $29.6 \%$ while $T_{\text {ripple }}$ during FEM analysis is $42.8 \%$. For torque ripple, the difference between measurement and FEM is $30 \%$.

Table 6. Torque ripple

\begin{tabular}{lllll}
\hline Type & $T_{\max }[\mathrm{Nm}]$ & $T_{\min }[\mathrm{Nm}]$ & $T_{\text {ave }}[\mathrm{Nm}]$ & $T_{\text {ripple }}[\%]$ \\
\hline Measurement & 0.31 & 0.23 & 0.27 & 29.6 \\
FEM & 0.34 & 0.22 & 0.28 & 42.8 \\
\hline
\end{tabular}

\section{CONCLUSION}

In this paper, winding arrangement of new type hollow rotor had been discussed. Hollow rotor has higher performance compared to other BLDC motor design because it minimize the unused flux below permanent magnet and maximize torque produce by the motor. Four winding arrangement is selected and design process for hollow rotor is carried out by using desired parameter. Structural comparison in term of coil vector and winding arrangement is analyzed by using FEM. Four sizes of coil diameter had been selected in order to select the best coil size. 9 slot 8 pole design with $0.6 \mathrm{~mm}$ size of coil diameter is selected for fabrication. Measurement and FEM result is compared in term of backemf and torque where it has percentage differences of $7.4 \%$ and $8 \%$, respectively.

\section{ACKNOWLEDGEMENTS}

The author would like to thank Skim Zamalah UTeM and Universiti Teknikal Malaysia Melaka (UTeM) for providing the research grant (PJP/2017/FKE/HI12/S01537, GLuar/PPRN/2017/FKECERIA/G00050 and GLuar/SURIAGIANT/2017/FKE-Ceria/100020).

\section{REFERENCES}

[1] M. Barcaro, "Performance Evaluation of an Integrated Starter Alternator using an Interior Permanent Magnet Machine," IET Electronic on Power Applied, vol.4, pp.539-546, 2010.

[2] T. Yoon, "Magnetically Induced Vibration in a Permanent-Magnet Brushless DC Motor With Symmetric Pole-Slot Configuration," IEEE Transactions on Magnetics, vol. 41, pp. 2173-2179, 2005.

[3] Z. Q. Zhu and D. Howe, "Influence of Design Parameters on Cogging Torque in Permanent Magnet Machines," IEEE Transaction Energy Conversion, vol. 15, pp. 407-412, 2000.

[4] J. Hur and B. W. Kim, "Rotor Shape Design of an Interior PM type BLDC Motor for Improving Mechanical Vibration and EMI Characteristics," Journal of Electrical Engineering and Technology, vol. 5, pp. 462-467, 2010.

[5] Z. Q. Zhu, M. L. Mohd Jamil, and L. J. Wu, "Influence of Slot and Pole Number Combinations on Unbalanced Magnetic Force in Permanent Magnet Machines," Energy Conversion Congress and Exposition (ECCE), 2011 IEEE, pp. 1-8, 2011.

[6] S. M. JafariShiadeh, M. Ardebili, "Three-Dimensional Finite-Element-Model Investigation of Axial-Flux PM BLDC Machines with Similar Pole and Slot Combination for Electric Vehicles," Power and Energy Conference at Illinois (PECI), 2015 IEEE, pp. 1-4, 2015.

[7] K. O. Sung, C. S. Hong, and P. Han, "Flux Fluctuations in Rotor Core According to PoleSlot Combination," 2012 IEEE Vehicle Power and Propulsion Conference, pp. 1045-1047, 2012.

[8] L. Ma, M. Sanada, S. Morimoto and Y. Takeda, "Prediction of Iron loss in rotating machines with rotational loss include," IEEE Transactions on Magnetics, vol. 39, pp. 2036-204, 2003.

[9] H. Nam, K. H. Ha, J. I. Lee, J. P. Hong and G. H. Kang, "A study on iron loss analysis method considering the harmonics of the flux density waveform using iron loss curves tested on Epstein samples," IEEE Transactions on 
Magnetics, vol. 39, pp. 1472-1475, 2003.

[10] V. Mostafa, N. Arne, N. Robert, D. L. Robert and R. Terje, "Influence of Pole and Slot Combinations on Magnetic Forces and Vibration in Low-Speed PM Wind Generators," IEEE Transactions on Magnetics, vol. 50, pp. 1-11, 2014.

[11] P. M. Lindh, H. K. Jussila, M. Niemela, A. Parviainen, and J. Pyrhonen, "Comparison of concentrated winding permanent magnet motors with embedded and surface-mounted rotor magnets," IEEE Transactions on Magnetics, vol. 45, no. 5, pp. 2085-2089, 2009.

[12] J. Yang, G. Liu, W. Zhao, Q. Chen, Y. Jiang, L. Sun, et al., "Quantitative comparison for fractional-slot concentrated-winding configurations of permanent-magnet vernier machines," IEEE Transactions on Magnetics, vol. 49, pp. 3826-3829, 2013.

[13] S. U. Chung, J. M. Kim, D. H. Koo, B. C. Woo, D. K. Hong, and J. Y. Lee, "Fractional slot concentrated winding permanent magnet synchronous machine with consequent pole rotor for low speed direct drive," IEEE Transactions on Magnetics vol. 48, pp. 2965-2968, 2012.

[14] A. S. Abdel-Khalik, S. Ahmed, A. Massoud, and A. Elserougi, "An improved performance direct-drive permanent magnet wind generator using a novel single layer winding layout," IEEE Transactions on Magnetics, vol. 49, pp. 5124-5134, 2013.

[15] S. Lee, Y. J. Kim, and S. Y. Jung, "Numerical investigation on torque harmonics reduction of interior PM synchronous motor with concentrated winding," IEEE Transactions on Magnetics, vol. 48, pp. 927-930, 2012.

[16] S. K. Lee, G. S. Kang, and J. Hur, "Finite Element Computation of Magnetic Vibration Sources in $100 \mathrm{~kW}$ two Fractional-slot Interior Permanent Magnet Machines for Ship," IEEE Transactions on Magnetics, vol. 48, pp. 867$870,2012$.

[17] A. M. EL-Refaie, "Fractional-slot Concentrated-windings Synchronous Permanent Magnet Machines: Opportunities and challenges," IEEE Transactions on Industrial Electronic, vol. 57, pp. 107-121, 2010.

[18] A. M. EL-Refaie, "Fractional-slot concentrated-windings: A paradigm shift in electrical machines," in Proceeding IEEE WEMDCD, Mar. 2013, pp. 24-32, 2013.

[19] F. Libert and J. Soulard, "Investigation on Pole-slot Combinations for Permanent-Magnet Machines with Concentrated Windings," in Proceeding ICEM, 2004, pp. 1-6, 2004.

[20] Y. S. Chen, Z. Q. Zhu, and D. Howe, "Vibration of PM Brushless Machines having a Fractional Number of Slots Per Pole," IEEE Transactions on Magnetics, vol. 42, pp. 3395-3397, 2006.

[21] G. Dajaku and D. Gerling, "Magnetic radial force density of the PM machine with 12-teeth/10-poles winding topology," in Proceeding IEEE IEMDC, May 2009, pp. 1715-1720, 2009.

[22] N. Bianchi, S. Bolognani, M. D. Pre, and G. Grezzani, "Design considerations for fractional-slot winding configurations of synchronous machines," IEEE Transactions on Industrial Application, vol. 42, pp. 997-1006, 2006.

[23] R. N. Firdaus, S. Farina, R. Suhairi, K. A. Karim, F. Azhar, A. Khamis and M. Norhisam, "Improvement of Torque Density Spoke Type BLDC Motor Using New Hollow Rotor Topology," International Review of Electrical Engineering (I.R.E.E.), vol. 12, pp. 19-25, 2017.

[24] R. N. Firdaus, S. Farina, R. Suhairi, K. A. Karim, J. Auzani, S. Tole and M. Norhisam, "Design of Hollow-Rotor Brushless DC Motor," International Journal of Power Electronics and Drive System (IJPEDS), Vol. 7, pp. 387-396, 2016.

[25] S. Ohira, N. hasegawa, I. Miki, D. Matsuhashi, and T. Okitsu, "Torque Characteristics of IPMSM with Spoke and Axial Type Magnets," SPEEDAM 2012 - 21st International Symposium on Power Electronics, Electrical Drives, Automation and Motion, pp. 818-821, 2012.

[26] Y. S. Chen, Z. Q. Zhu, and D. Howe, "Vibration of PM Brushless Machines Having a Fractional Number of Slots Per Pole," IEEE Transactions on Magnetics, vol. 42, no. 10, pp. 3395-3397, 2006.

[27] Z. Q. Zhu,H. David Howe, and C. C. Chan, "Improved Analytical Model for Predicting the Magnetic Field Distribution in Brushless Permanent-Magnet Machines," IEEE Transactions on Magnetics, vol. 38, no. 1, pp. 229238, 2002.

[28] M. S. Ahmad, A. A. M. Nurul, I. Dahaman, "Permanent Magnet Brushless Machine with Minimum Difference in Slot Number and Pole Number," 2nd IEEE International Conference on Power and Energy (PECon 08), December 1-3, 2008, pp. 1064-1069.

[29] M. S. Ahmad, A. A. M. Nurul, F. Maher, I. Dahaman, "Improved Torque in PM Brushless Motors with Minimum Difference in lot number and pole number," International Journal Power and Energy Conversion, vol. 3, pp. 206219,2012 